TI 2019-007/VIII

Tinbergen Institute Discussion Paper
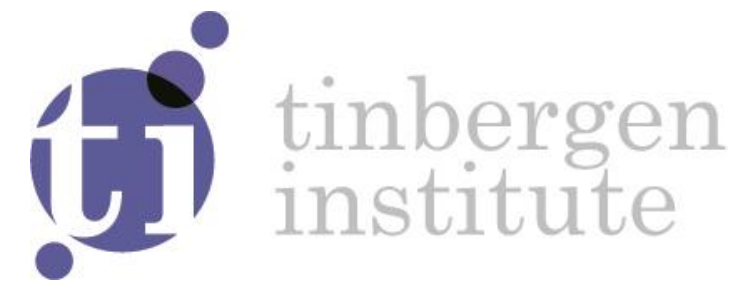

\title{
Tradable permits to manage urban mobility: market design and experimental implementation
}

Devi Brands ${ }^{1}$

Erik (E.T.) Verhoef ${ }^{1}$

Jasper Knockaert ${ }^{1}$

Paul (P.R.) Koster ${ }^{1}$ 
Tinbergen Institute is the graduate school and research institute in economics of Erasmus University Rotterdam, the University of Amsterdam and VU University Amsterdam.

Contact: discussionpapers@tinbergen.nl

More TI discussion papers can be downloaded at http://www.tinbergen.nl

Tinbergen Institute has two locations:

Tinbergen Institute Amsterdam

Gustav Mahlerplein 117

1082 MS Amsterdam

The Netherlands

Tel.: +31(0)205984580

Tinbergen Institute Rotterdam

Burg. Oudlaan 50

3062 PA Rotterdam

The Netherlands

Tel.: +31(0)10408 8900 


\title{
Tradable permits to manage urban mobility: market design and experimental implementation*
}

\author{
Devi K. Brands, Erik T. Verhoef, Jasper Knockaert \& Paul R. Koster
}

\begin{abstract}
Congestion levels have grown substantially in recent years, while the traditional economic response to congestion - road pricing - remains politically infeasible in most locations. Tradable permits are likely to be a more viable alternative, because they do not require a net financial flow from road users to the government. It is therefore the right moment to design and empirically test tradable permit schemes for managing urban mobility. This paper presents and empirically tests a complete design of a market for tradable permits, both in terms of the conceptual set-up of the market as well as its technical implementation. The design is evaluated against a number of criteria, including: transparency and containment of transaction costs, stability of permit prices in relation to the dynamic equilibrium on the mobility market and the prevention of undesirable speculation and fraud. We present evidence of the empirical functioning of this market, using the results of a conducted lab-in-the-field experiment with virtual mobility behaviour and real financial incentives.
\end{abstract}

\section{Introduction}

Congestion levels have grown substantially over the past years in many locations, owing to the economic upsurge and the ongoing clustering of human activities. The traditional Pigouvian economic response to congestion - road pricing - appears, however, to often remain politically and socially infeasible. This may help explain why a potential alternative to road pricing, namely tradable permit schemes for road transport, has received growing attention in the recent academic literature (e.g. Yang and Wang (2011); Nie and Yin (2013); Xiao et al. (2013); Akamatsu and Wada (2017); de Palma et al. (2018)). The idea to use tradable permits for the regulation of externalities is not new. Already in the 1960s, Crocker (1966) and Dales (1968) proposed systems of transferable discharge permits to regulate atmospheric pollution and water pollution respectively. The idea to also use tradable permits for the regulation of road transport externalities has been around for already quite some time as well (e.g. Verhoef et al. (1997)), but has often been regarded as a theoretical possibility rather than a realistic policy option. An important impediment has been the transaction costs associated with the trade of permits, especially in situations with a high number of "atomistic" road users, and the monitoring costs involved in securing compliance. Rapid technological progress has led to substantial decreases in these costs, through the possibility of internet trading and automated vehicle detection and monitoring. This may explain the recent upsurge in academic attention for the measure.

Permit schemes have already been successfully implemented in the past to ensure internalization of environmental externalities. The first large scale implementation of tradable permits has been in the USA and successfully reduced emissions of sulphur dioxide, $\mathrm{SO}_{2}$, substantially (Schmalensee et al., 1998). Joskow et al. (1998) investigated the efficient market assumption for this case and found evidence that an efficient private market for allowances developed over time, further strengthening the case for using tradable permits as a policy measure. Another well known large scale application of tradable permits has been the emission trading scheme (ETS) of the European Union, which creates a market for carbon emissions. Although its effect on emissions may be less clear cut than in the case

${ }^{*}$ We thank the audiences of the 2018 ITEA conference in Hong Kong and of the spatial economics seminar at the VU Amsterdam for useful comments. This work is supported by funding of the Netherlands Organization for Scientific Research (NWO) as part of the U-SMILE project 438-15-176, and by the European Union's Horizon 2020 program as part of IP-SUNTAN project 5597288, which is gratefully acknowledged. 
of $\mathrm{SO}_{2}$ in the USA, Martin et al. (2015) show there is reason to believe that it helped in reducing emissions. Concerns over low permit prices, resulting from a high number of permits initially allocated remain (Christiansen et al., 2005), despite the fact that the price has recently increased rapidly (from approximately $€ 8$ at the start of 2018 to well over $€ 20$ towards the end of 2018). Despite these implementations in environmental settings, to the best of our knowledge, no field experiments with tradable permits for transportation have taken place yet.

Tradable permits nevertheless provide some important advantages over road pricing. The first advantage is that it does not require a net financial flow from road users to a governing authority, which is likely to make it a politically more feasible policy measure than road pricing. Past experiments in the Netherlands have provided evidence that rewarding avoidance of externality causing behaviour can be an effective alternative measure as well (Knockaert et al., 2012), but it may cause other political and economic issues as this requires raising funds to payout rewards.

The second advantage is that the actual distribution of costs and benefits can be easily influenced by the initial allocation of permits, making it a policy that could be used as an easy and natural way of providing a subsidy to specific groups of road users. Addressing redistributional concerns through the initial grandfathering of permits is a more direct and more flexible way than what is usually feasible for pricing-and-recycling schemes, which can further enhance the social and political acceptability. The reason behind this is that recycling is often tied to existing taxes, or takes the form of public expenses or investments, which are difficult to direct to specific groups or individuals, whereas the distribution of tradable permits is not.

Given these advantages, the time is right to design and empirically test tradable permit schemes for managing urban mobility that can be implemented in the field. This paper contributes to the existing literature on tradable permits in a transportation setting by doing exactly that. The paper starts by presenting a complete design of a market for tradable permits, in terms of the conceptual set-up of the market and its technical implementation. The design is evaluated against a number of criteria: transparency and containment of transaction costs, the stability of permit prices in relation to the equilibrium on the road, the efficiency of the market and the prevention of undesirable speculation (as opposed to desirable speculation) and fraud. We then present evidence of the empirical functioning of this market using the results of a lab-in-the-field experiment. We show that the price stayed mostly within the equilibrium range, while the sum of used and currently owned permits stayed close to the defined policy goal. Participants traded virtual parking permits in an experimental game with real financial incentives and virtual mobility behaviour, using a permit market design according to the principles outlined in this paper. Overall, the results of the lab-in-the-field experiment are promising and support the notion that tradable permits can be a viable alternative to pricing in a transportation setting. Previous work has suggested this on the basis of modelling work in which efficient trading and efficient working of the market for tradable permits was pre-supposed. Our study confirms that individuals indeed do understand and use a system of tradable mobility permits in the way this is intended from underlying theory. The paper finishes by discussing the understanding and behaviour of participants, and the important insights from the conducted survey.

\section{Market Design}

Conventional economic theory predicts that mobility permits will eventually be efficiently used by travellers with the highest marginal benefits for their use, if they can be traded freely. However, the market for tradable mobility permits needs to satisfy certain conditions in order for it to function in such a desirable fashion, ensuring that the efficient allocation of permits is reached through trade. This section describes these conditions, and our proposed market design seeks to incorporate them. We design a market for a simple tradable permit system pertaining to a finite period, without personal banking of permits between periods. This implies that permits need to be used or sold during the defined time frame and cannot be saved for later periods. The idea of the simple system is that participants would be allocated an initial number of permits that they can use for a predetermined and clearly communicated time frame (e.g. a day, a week or a month). 


\subsection{Transaction costs and transparency}

For tradable permits to be a desirable policy compared to politically less feasible alternatives, one of the conditions that the system should satisfy is that transaction costs are low. In a model of tradable permit activity that does include transaction costs, the initial allocation of permits can be shown to affect the final equilibrium when marginal transaction costs are nonconstant (Stavins, 1995). An extensive literature from the field of environmental economics (e.g. Tietenberg (1985)) suggests that substantial transaction costs are in practice indeed present and influencing the final outcomes. Also more recent work, focussing on a transportation setting, shows that transactions costs can divert the system from the desired equilibrium (Nie, 2012).

Designing the market for tradable permits such that transaction costs are very low increases the likelihood of reaching a more efficient final equilibrium. Having a transparent market with easily accessible price information for all its participants will help in this respect.

As discussed in Section 1, one of the important advantages of tradable mobility permits is that they provide a possibility for internalization of the externality without the need for a money flow between road users and the government. An intuitive set-up for such a market would be to have consumer to consumer trading, which would indeed ensure that there is no net money flow between road users and the government. However, one important disadvantage of consumer to consumer trading is that users themselves have to search for a potential seller or buyer. Consumer to consumer trading also requires users to negotiate the price with one another, which also takes time and effort. These two disadvantages likely increase the transaction costs. As these transaction costs make it less likely that the market leads to an efficient allocation of distributed permits, this paper proposes an alternative approach, and presents a design of a market that reduces that transaction costs substantially.

Our market design lets users trade with a price setting intermediary, which we will further refer to as the bank. Designing the system such that users can buy or sell permits at a known and easily accessible "location" (e.g. in an application on their smartphone) at a single, public price ensures that search costs and negotiation costs are (close to) zero. Price information is easily accessible and the same for all users, which makes it a transparent solution.

This system does also have its drawbacks. The main drawback compared to consumer to consumer trading is that it provides no guarantee for exact budget neutrality for the owner of the bank (e.g. a local government). Users can be expected to, on aggregate, have a tendency to buy (additional) permits when prices are relatively low, and to sell permits when prices are relatively high, which overall can be expected to result in a bank deficit. The relative size of this deficit (compared to the total value of the permits used) can be characterized as the degree of budget neutrality.

\subsection{Permit price dynamics}

A tradable permit scheme is a market-based policy instrument which ensures that the desirable level of the activity is efficiently allocated over participants in the market. In a transportation setting, this desired level of activity for a specified period could for example be a specific number of trips during the peaks in that period, for road users on a specific route. We refer to this quantity target as $Q$.

A tradable permit scheme allows the managing authority of the scheme to choose the desired $Q$, while subsequently letting the market determine the corresponding price of the permits. When using a bank from and to which permits can be bought and sold at a single price, one needs an algorithm to set this permit price.

Having a quantity goal, while not knowing the corresponding equilibrium price, asks for a price adjustment algorithm that lets the price fluctuate in such a manner that it ensures moving towards an efficient allocation of the quantity goal $Q$. The advantage of this is that if participants become more flexible in the medium to long term, the equilibrium price will automatically decrease, while still ensuring moving towards the same equilibrium quantity. A system with a fixed fee, reward or permit price would, without intervention, result in less permits used than desirable in such a case.

When designing the algorithm, a trade-off has to be made between volatility of the permit price and the time it takes to reach the equilibrium in which $Q$ permits are efficiently allocated. More volatility means more risk of overshooting (moving from a price lower than the equilibrium price to one that 
is higher or vice versa) in fluctuations around the equilibrium price, while more stability means that the movement towards the equilibrium price is slower. A side-effect of overshooting is that it provides more opportunity for participants to buy when the price is relatively low and sell when it is relatively high, which on aggregate may be expected to raise the bank deficit.

Many different algorithms can be developed and used to guide permit price changes. It is natural to let the direction of the price change depend on the instantaneous sign of the distance from the goal, defined as the difference between the target quantity $Q$ and the number of permits "in the market" (i.e. the sum of the number of permits currently owned by participants and the number of permits used so far in that period). The size of the price adjustment can be fixed, but it is also possible to have it for example depend on that same distance from the goal.

A very simple algorithm that ensures moving towards the policy goal, while keeping price volatility and the expected bank deficit low is given below. $Z_{t}$ is the number of permits owned by road users at time $t, U_{t}$ is the total number of permits that has been used up until $t$ and $\delta$ is the step-size of the price adjustment and is therewith a parameter that can be set at a desired level.

$$
P_{t}= \begin{cases}P_{t-1}+\delta & \text { if } Z_{t}>Q-U_{t} \\ P_{t-1} & \text { if } Z_{t}=Q-U_{t} \\ P_{t-1}-\delta & \text { if } Z_{t}<Q-U_{t}\end{cases}
$$

$P_{t}$ stands for the new price at moment $t$, after the most recent transaction has been made, and $P_{t-1}$ represents the prevailing price at the time of that transaction. If currently more permits are in the market than the remaining target at time $t, Z_{t}+U_{t}>Q$, the price increases by $\delta$, making it more attractive for participants to sell some of their permits. Similarly, if at time $t$ less permits are in the market than desired, the permit price decreases by $\delta$, to make it more attractive for participants to buy additional permits.

A final decision concerns the frequency of price adjustments. Naturally, it is desirable to have this frequency vary with the intensity of trade. The algorithm reflects this, and lets the price change after each transaction. Letting the price change after each transaction makes the price pattern dynamically dependent on market activity. It ensures that, if many people are active in the market, the price adjusts quicker. Likewise, the price does not change during long periods of inactivity, which could for example happen in thin markets during the night time.

\subsection{Speculation}

The main idea of tradable permits from the perspective of the individual or firm is that the agent can buy or sell permits in order to be better off. This could also mean that it is beneficial to buy at the current price, while it may be good to sell again at a later moment. Anticipating price changes, and acting on them by buying or selling permits to resell or rebuy at a profit later, can be seen as desirable speculation in the sense that it leads to prices reflecting aggregate valuations and expectations. On aggregate, the expected effect of this desirable speculation is that the price moves towards the equilibrium price sooner. The reasoning behind this is that when prices are relatively low (high), more people will expect the price to increase (decrease) in the near future and will show a tendency to buy (sell), therewith ensuring the price starts to move up (down) sooner. Allowing participants in the market to buy and sell whenever they prefer ensures that this "desirable" type of speculation is enabled.

For the design of the market, it is however also important to limit undesired speculation. Although individuals who speculate (and possibly manipulate) the market may be interesting from a research perspective, it may hamper the effectiveness of the tradable permit scheme in reaching its intended goal. Moreover, policy makers are likely to find the existence of large profits from speculations and manipulation unattractive from the distributional viewpoint, even if efficiency is not affected.

When having the price change after each transaction, some participants are likely to become aware of this, and may look to manipulate the price for their own benefit. An example might be when the system would allow an individual to benefit from first selling one permit, and then buying back two. This, and other types of undesired speculation and manipulation, can to a large extent be prevented 
in the studied setting by (1) introducing a small transaction fee, (2) letting participants trade permits by the piece, and (3) introducing a maximum to the number of permits participants can own. The combination of introducing a very small transaction fee and letting participants trade permits by the piece limits the possibilities of benefiting from price manipulation, and makes it unattractive to attempt to do so. Keeping the transaction fee very low ensures that it has little effect on trading and use of permits, and therewith on the final equilibrium that is reached. It will also only have a negligible effect on the final budgets of people who do not engage in undesired speculation and therefore only trade up to a couple of times per week. The third additional constraint is to introduce a maximum number of permits that a participant can own, and equate it to the maximum number the individual can still meaningfully use at time $t$. If a permit for example provides the owner the right to drive during the morning peak on a workday, and the defined time frame during which the permits are valid is a week, there will be no need to own more than five permits at the start of the week (other than for speculation purposes), as there are only five remaining morning peaks on workdays. Given this constraint, the maximum allowed number of permits then decreases over the week, as the number of morning peaks remaining during that week decreases as well.

\section{Empirical implementation}

The market design has been empirically implemented and tested in December 2017, during a so-called lab-in-the-field experiment. The lab aspect is that mobility choices were virtual and that we have used an experimental setting that allows, via the pay-off structure in the game, for a tight control over mobility "preferences" of participants. The field aspect of the experiment is that it has been conducted in a naturalistic setting, while targeting the theoretically relevant population.

When implementing a scheme for tradable mobility permits in the field, the required use of permits will naturally be restricted to a specific location or area and a specific time frame. There is, however, no direct reason to put any further limits on the trading of these permits to a specific location or time of day. Participants were therefore allowed to trade on their smartphones whenever and wherever it suits them best. An important further consideration in designing the experiment in this way is that we wanted to ensure that trading of permits would not be condensed in time into a relatively short lab-session (say 75 minutes to replicate what in reality would be a full 7-day period), as is usually the case in experiments on participant behaviour in a dynamic market setting (see e.g. Hommes et al. (2007)). Instead, we spread out the trading period over the course of a full week, making the market dynamics more in line with trading as it would likely take place during a real application of mobility permits. The specific concern is that respondents are likely to react to price volatility, which would be increased for a condensed trading period. This combination of allowing participants to choose when and where they trade on their smartphone, and letting the trading period be the same as would be the case in a field experiment, comprises what we mean with a naturalistic setting.

Participants of the lab-in-the-field experiment were recruited from a pool of former Wild van de Spits participants, of whom we know that they regularly commute to work by car, and that they are interested in voluntarily participating in this type of experiments. This is the theoretically relevant population as, if shown to have potential as a traffic management tool, tradable mobility permits will likely be firstly applied in the field with voluntary participants who are experienced road users.

\subsection{Choice setting}

To be able to test the designed market for tradable permits, and the understanding of participants of the concept of tradable permits and how to trade them, the choices that participants faced during the experiment were formulated as virtual parking choices. All relevant attributes of the parking choice were expressed in monetary terms and were translated into the final budget that participants would receive in real money after the experiment. This enables us to control all "preferences" related to the use of the permits, while preferences on trade moments and frequencies remained uncontrolled and for participants to choose. The advantage of this over an experiment involving real mobility behaviour is that unobserved participant-specific circumstances are less likely to play a role in whether or not a participant decides to use a permit on a specific day of the week. One disadvantage is that it may 
Week 1

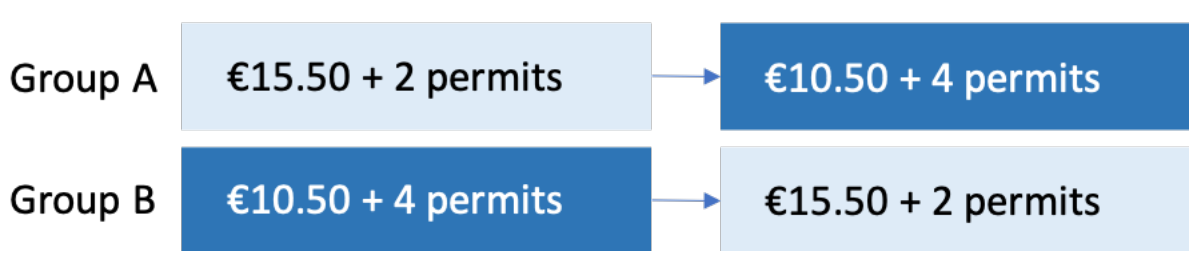

have made the choice somewhat more complicated for participants.

Participants participated for two weeks, and received a starting budget (expressed in Euro) and a number of permits at the beginning of each of those two weeks. They were able (and instructed) to make one parking choice on each working day during each of the two weeks.

In order to incentivise participants to take the experiment serious, they were informed that the sum of the remainder of their personal virtual budgets at the end of both weeks would be transferred in real money to their personal bank account after the experiment had ended. They were explicitly encouraged to participate smartly in order to increase the amount of money they would receive on their bank account, so as to increase our learning of how successful we were in preventing undesired speculation.

For the setting of the experiment, participants were told they had to imagine that every working day, they use the vehicle to get to work, and at work, they had the choice of paying for parking in two ways: by paying a regular parking fee (from their personal budget), or by using a tradable parking permit. Using a permit means that it is not necessary to pay the tariff that day, and vice versa. The price of permits varied endogenously over time, depending on the aggregate trading behaviour and usage, in the way described in Section 2.2. Participants could buy and sell permits at any moment, against a prevailing price of permits. The parking tariff is the given, fixed price of parking for a whole day. This tariff varied between weekdays. Each participant was assigned a permutation of the tariff values $€ 1, € 2, € 3, € 4$ or $€ 5$, and could see in advance in the web application which tariff would be charged on which day. ${ }^{1}$ This means that the desirability of using a permit varied between the days for each participant, and that it varied between participants for every given day.

At any moment during the experiment, participants could open the web application and see the prevailing price, the remainder of their personal budget, and the number of permits in possession. Participants could already start trading during the weekend preceding the working week during which they would have to make their parking choices.

Participants were randomly allocated to one of two groups, group A and group B. Group A started, in the first week, with a relatively high budget of $€ 15.50$ and 2 permits, while B started with a budget of $€ 10.50$ and 4 permits in that week. As illustrated by Figure 1, the roles were reversed in the second week, such that both groups started under each condition once.

Participants were made aware of the fact that they were split up into two groups of approximately the same size, and what the starting budgets and allocated number of permits were for both groups. It was stated that the price for permits changes as participants buy or sell permits. From the provided information, participants could in principle form an expectation of the equilibrium price range, and predict the rational equilibrium (see Section 3.2). We used the price setting algorithm as introduced and discussed in Section 2.2. With a small transaction fee of $€ 0.01$ and a step size of $\delta=0.01$, participants could not easily earn money by repeatedly buying and directly selling again.

Finally, we introduced a fee that can be seen as a virtual parking fine to provide an extra incentive for active participation. Participants who did not make an active parking choice on one of the weekdays

\footnotetext{
${ }^{1}$ When comparing this choice setting with a tradable permit scheme for tradable peak hour permits, the varying of the parking tariff can be interpreted as (scheduling) costs to an individual to avoid the peak, therewith capturing differences in flexibility to travel to work outside the peak (or by alternative transport) over different days, as well as differences in flexibility between individuals on any given working day.
} 
during the two weeks of the experiment were charged $€ 2$ at the end of that day while the parking choice was automatically made for them and involved paying the daily tariff, independent of its level. This means that the minimum pay-off from actively making a parking choice, a decision and action that would presumably require less than a minute, was $€ 2$. This, and the rest of the choice setting, was clearly communicated to participants before the experiment started, both in writing as well as through a short instruction video.

In total, 81 (66) participants made at least 1 parking choice during the first (second) week of the experiment, and 79 people filled out the survey after the trading part of the experiment had ended. The number of parking choices made per day by participants varied between 46 and 70 (48 and 60) during the first (second) week.

\subsection{Price dynamics}

The permit price started both weeks at $€ 2.50$, and was expected to mainly remain within the equilibrium range, $€ 2$ - $€ 3$. Participants could in principle compute this range by using the information that there were on average three permits per participant (two approximately equally sized groups starting with 2 and 4 permits respectively). This means that participants are expected to use 3 permits per week on the high tariff days (tariffs of $€ 3, € 4$ or $€ 5$ ), and pay the tariff from their personal budget on the low tariff days ( $€ 1$ or $€ 2$ ). This leads to the stated equilibrium price range (note that there is not a single unique equilibrium price level), where participants starting with 2 permits are expected to buy one more permit for usage, while those starting the week with 4 permits are expected to sell one permit.

Figure 2: Price development

week 1

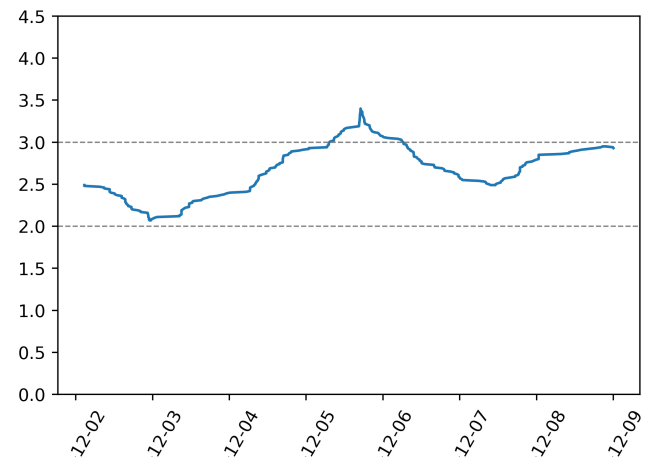

week 2

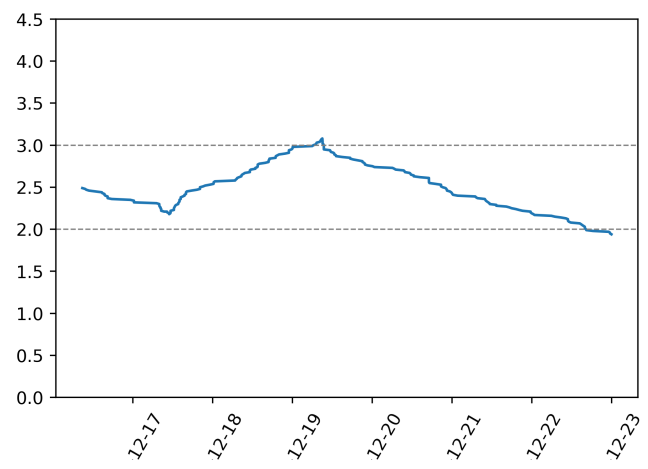

Figure 2 displays the price development over time for both weeks of the experiment, with the price of permits in euros on the $\mathrm{y}$-axis, and the days of the week on the $\mathrm{x}$-axis. It shows that the price mainly stayed within the equilibrium range (demarcated by the two dotted horizontal lines) during both weeks, returning to the range relatively quickly when getting outside of it. The average permit price was $€ 2.73$ ( $€ 2.53)$ and it varied between $€ 2.07$ and $€ 3.40$ (€1.94 and $€ 3.08$ ) in week 1 (week $2)$.

\subsection{Market evaluation}

The fact that we control preferences does allow us to observe to what extent permits are used when most beneficial to participants. In a set-up with very low transaction costs, participants would be expected to use permits in a rational manner; i.e. when not doing so would be more costly to them. In well over $90 \%$ of the parking choices made in our lab-in-the-field experiment, participants do indeed choose the option that is most beneficial to them. We discuss this choice behaviour of participants in more detail in Section 3.4.

The fact that the permit price stayed mostly within equilibrium range during the two weeks of the 
experiment, and returned relatively quickly when getting outside of the range, provides a first indication that the price setting algorithm did what it was designed for. The exception to this at the end of the second week can, under closer inspection of the choice and trade data of the few participants who were still active that time of day, be attributed to some participants choosing and trading irrationally with regard to their personal budget. The price would most likely have returned to the equilibrium range if the period had lasted longer, like it did in other cases where it got out of the equilibrium range.

The purpose of the price algorithm in combination with the free trade of permits is to ensure efficient allocation of permits over all participants while remaining close to, or moving towards, the goal of using $Q$ permits. In our empirical implementation, $Q$ permits were distributed initially at the start of the week. This means that, in order to stay close to the goal, the total number of permits bought should be close to the total number of permits sold. Figure 3 shows the cumulative number of buys and sells by participants over week 1 and week 2 . The fact that both stay indeed close to one another suggests our price algorithm does what it was designed for.

Figure 3: Cummulative transactions

week 1

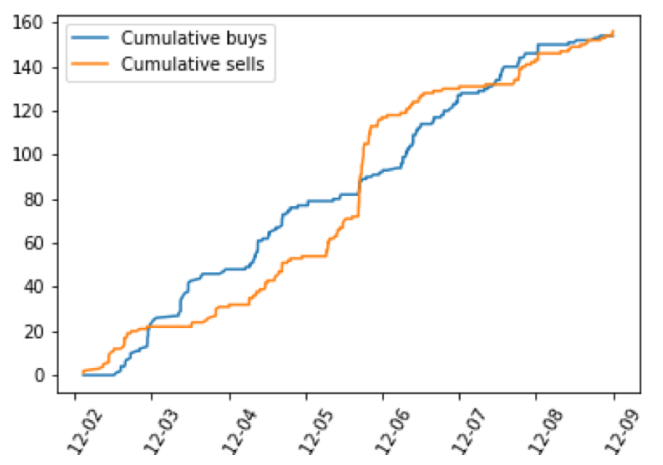

week 2

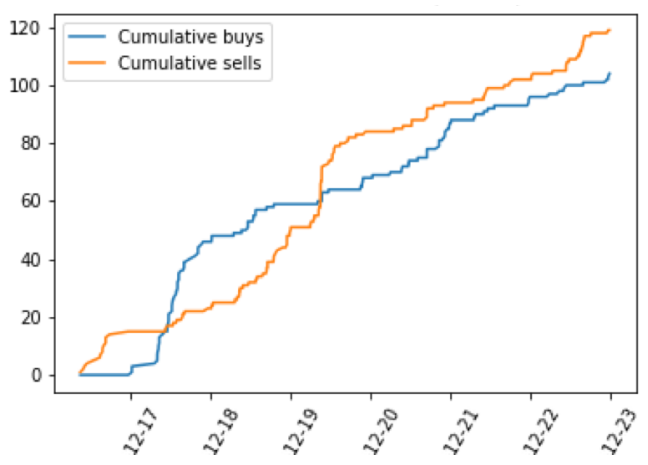

As our market design is supposed to allow for desirable speculation, while preventing undesired speculation, a final aspect of the evaluation of the functioning of the designed market is to see if our design indeed succeeds in this respect. When actively participating, participants do on average earn money compared to a scenario of trading at random moments, which is indeed an indication of participants anticipating price changes and acting on them (i.e. desirable speculation). Although some participants ended up with budgets that are substantially higher than the trading at random moments scenario (maximum final budget was $€ 12.34$ and $€ 13.67$ in the first and second week respectively), we would classify this as within the range of desirable speculation, as well timed purchases and sells of two to three permits could already result in this. Moreover, undesired speculation of the two types discussed above did not occur: owning more permits than the number of choices remaining was simply impossible, and repetitive alternating transactions, possibly motivated to affect the permit price, was not observed. More details on the final budgets and participant behaviour follows in Section 3.4.

\subsection{Behaviour and feedback}

Another important assumption that needs to hold in order for tradable permits to result in an efficient equilibrium is that the trading agents make rational choices. Evidence from empirical studies focussing on trading individuals, (e.g. Kahneman et al. (1990), Baldursson and Sturluson (2011)), indicates that actual outcomes may in some cases deviate considerably from the standard theoretical predictions. We therefore also present insight into whether participants in our experiment choose and trade rationally, thus providing some first evidence on the rationality of participants that take part in a scheme with tradable mobility permits, and therewith on the extent to which they interpret the incentives from the scheme in the way these are meant to be interpreted according to the underlying theory.

We distinguish two types of rationality, instantaneous and intertemporal rationality. Instantaneous 
rationality refers in our set-up to rationality of the parking choice and whether, at the moment the parking choice is made, the chosen alternative does indeed maximize the final budget. Intertemporal rationality, on the other hand, here refers to trading behaviour and whether participants take their remaining daily tariffs into account and rationally anticipate price changes when making trading decisions, such that their final budget is maximized. Instantaneous rationality can easily be determined, and is discussed in Section 3.4.1. The degree of intertemporal rationality that participants reveal is less easily disentangled from observed behaviour, and is discussed in further detail in Section 3.4.2.

\subsubsection{Instantaneous rationality}

For the parking choice, participants choose each day between paying the fixed tariff or using a permit. At the moment the choice is made, the instantaneously rational choice is to pick the alternative that costs the least, therewith making a trade-off between the tariff and the current permit price. The fraction of choices that are in line with instantaneous rationality can therefore easily be computed by calculating the number of choices that are instantaneously rational over the total number of choices. Analysis of the collected data suggests a high degree of instantaneous rationality. In both weeks, more than $90 \%$ of the choices were instantaneously rational (approximately $93 \%$ and $94 \%$ in the first and second week respectively). The fraction of choices that are not instantaneously rational varies from $1.9 \%$ to $12 \%$ over the successive days. From Figure 4 we observe that especially on Tuesday and Wednesday in the first week this fraction is relatively high compared to the other days. The widely celebrated festivities of Sinterklaas (a Dutch holiday) took place that Wednesday, and the feast as well as the preparations the day before, might have played a role in this.

Figure 4: Instantaneous rationality per day

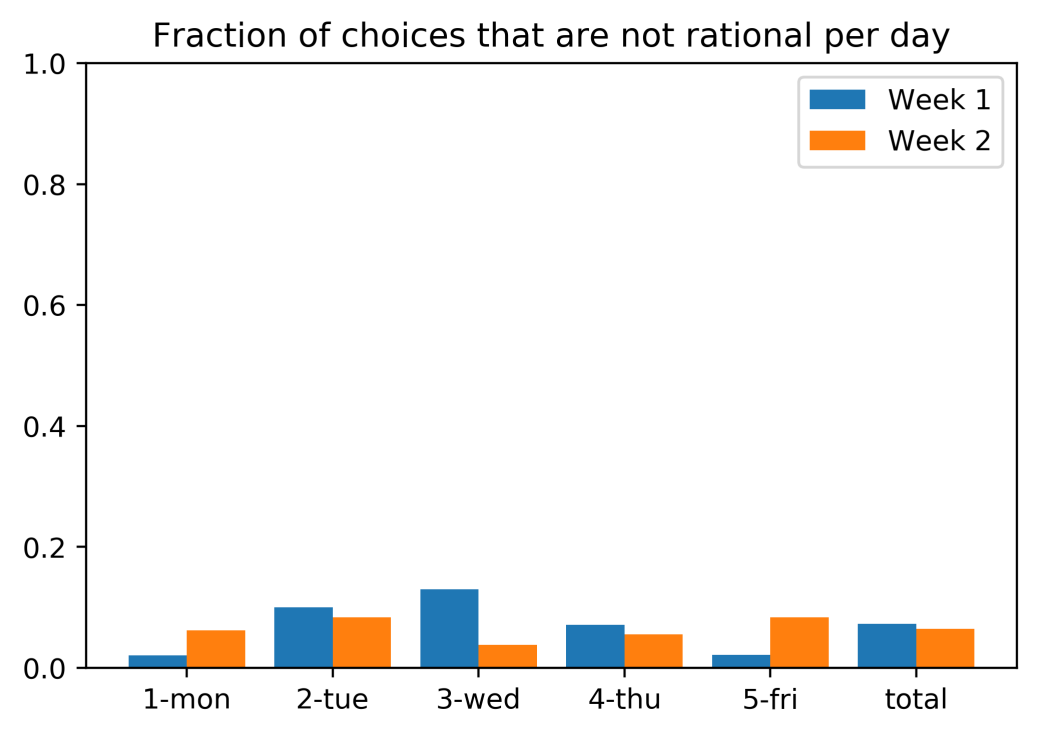

Interestingly, we furthermore observe that the level of instantaneous rationality is relatively low when it matters the least, as can be seen from Figure 5. This means that participants who, at the expense of their own final budget, choose the more expensive alternative, most often do so when the daily tariff is $€ 2$ or $€ 3$ and this mistake is therefore least costly, given the actual permit prices. This could either mean that it becomes more difficult for participants to determine which alternative is best for them at trade-offs near indifference, or that they care less about picking the best alternative in such situations as is does not make much of a difference for what they can earn with their participation. 
Figure 5: Instantaneous rationality per tariff value

week 1

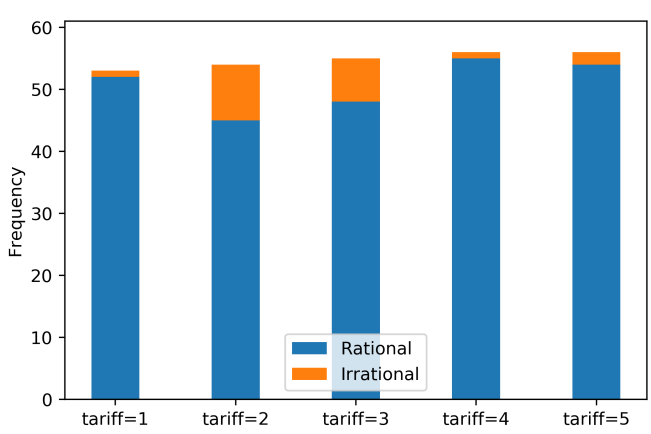

week 2

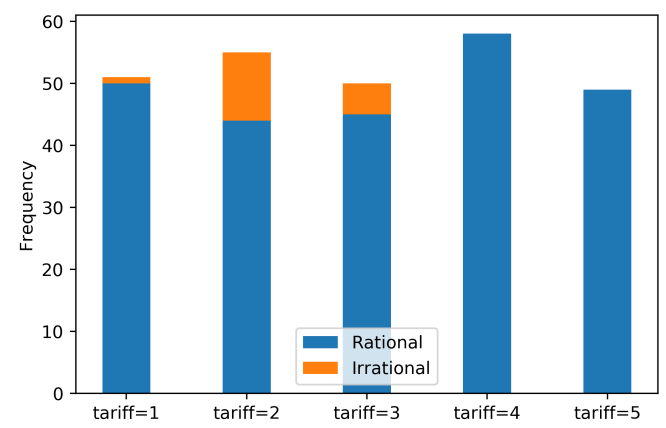

\subsubsection{Overall rationality}

Overall performance of participants' trading and choice behaviour, i.e. how well they did during the experiment overall, is reflected by the final budget at the end of each trading week. The final budget of participants provides an indication of the degree of instantaneous and intertemporal rationality combined, that concerns the rationality of the parking choice and trading behaviour respectively. To get an idea of what to expect in terms of final budgets, let us consider a scenario in which the permit price stays between $€ 2$ and $€ 3$ and participants do not trade for speculation purposes but only for personal use of the permits. Each participant would then only trade once, to either buy an additional permit or sell one of their permits (depending on whether they have started with 2 or 4 permits. If the participant follows the rational choice strategy, but trades at a random moment, the expected final budget is $€ 10$, as illustrated in Table 1 (using an expected permit price of $€ 2.50$ ). Independent of the group they are assigned to, rational participants will use their budget to pay the parking tariffs of $€ 1$ and $€ 2$, while using permits during the other days of the week. For those participants that do also trade smartly and try to earn some more money through their trading, the expected final budget would be somewhat higher than $€ 10$.

Table 1: Budget development

\begin{tabular}{|c|c|c|c|c|c|}
\hline Start of week & $€ 15.50$ & 2 permits & Start of week & $€ 10.50$ & 4 permits \\
\hline daily tariff & $\Delta$ budget & $\Delta$ permits & daily tariff & $\Delta$ budget & $\Delta$ permits \\
\hline & $-€ 2.50$ & 1 & & $€ 2.50$ & -1 \\
\hline$€ 2$ & $-€ 2$ & & $€ 5$ & & -1 \\
\hline$€ 3$ & & -1 & $€ 3$ & & -1 \\
\hline$€ 1$ & $-€ 1$ & & $€ 4$ & & -1 \\
\hline$€ 5$ & & -1 & $€ 2$ & $-€ 2$ & \\
\hline$€ 4$ & & -1 & $€ 1$ & $-€ 1$ & \\
\hline End of week & $€ 10.00$ & 0 permits & End of week & $€ 10.00$ & 0 permits \\
\hline
\end{tabular}

When only considering data of participants from whom we also obtained other personal characteristics and feedback through the conducted survey, and who made at least 3 parking choices during the specific week, the lab-in-the-field resulted in 97 observations of a final budget at the end of either of the two weeks of the experiment. We have estimated multiple OLS models; the results of which are presented in Table 2. These results provide first descriptive insights into how the final budget varies over participants. Results of regression model I show average deviation of the final budgets from the expected value of $€ 10$ for participants, grouped by the number of days on which they made a parking choice. The reference category concerns respondents who were active on 5 days of the week, meaning 
that they made a parking choice on every possible day. This reference category earned on average $€ 0.32$ more than the expected value, while participants who were active on only 4 out of 5 days (3 out of 5 days) earned on average approximately $€ 3.30$ ( $€ 6)$ less than their active peers. The results show that participants in the reference category earned approximately $€ 0.30$ on average with smart trading, compared to the budget development as presented in Table 1. This suggest that participants, at least those that are part of the reference group, also show a considerable degree of intertemporal rationality, besides the high degree of instantaneous rationality. In practice, this translates into buying when the price is low and selling when it is high. The fact that the steep segments of the cumulative curves in Figure 3, intersect lines from the other side of the market when these have become flat, underlines that many buyers (sellers) wait until prices have become relatively constant after a period of decreases (increases) before becoming active.

We calculate the expected loss of not making a parking choices, in order to interpret the final budgets of less active participants. For participants who made 4 out of 5 parking choices, the expected loss of not making one of the choices themselves can be computed by taking the difference between the expected cost when letting the system make the choice (automatically selecting to pay the tariff plus a fine of $€ 2$ ) and the expected cost when making the choice yourself.

$$
\begin{gathered}
\mathrm{E}(\text { cost of system choice })=\mathrm{E}(\text { tariff })+\mathrm{fine}=\frac{1}{5} \cdot € 1+\frac{1}{5} \cdot € 2+\frac{1}{5} \cdot € 3+\frac{1}{5} \cdot € 4+\frac{1}{5} \cdot € 5+€ 2=€ 5 \\
\mathrm{E}(\text { cost of own choice })=\frac{1}{5} \cdot € 1+\frac{1}{5} \cdot € 2+\frac{3}{5} \cdot \mathrm{E}(P)=\frac{1}{5} \cdot € 1+\frac{1}{5} \cdot € 2+\frac{3}{5} \cdot € 2.5=€ 2.10
\end{gathered}
$$

The difference between these two expected costs is the expected loss due to not making the choice yourself, which is $€ 5-€ 2.10=€ 2.90$. Following the same reasoning, the expected combined loss of not making the choice two times would be $2 \cdot € 2.90=€ 5.80$. The differences in average final budgets between de reference group and these two groups of participants, $€ 3.30$ and $€ 6$ respectively, are both not significantly different from this expected loss at conventional significance levels.

When including other variables, representing participant activity during the experiment and information obtained through survey responses, overall results remain very similar. Intertemporal rationality is, however, no longer captured by the constant, but explained by other factors instead. The results suggest that starting with a higher budget and lower number permits does not have a significant impact on the budget that participants end up with at the end of the week. Furthermore, participants did not earn significantly more during the second week compared to the first one, which suggests participants do not learn or get better in trading for their own benefit over this short period of time. The results also show that female participants do not end up with significantly more or less money. More active participants do on average earn more, as suggested by the significant estimate for activity level. This variable is the number of times a participant opened the web application to check the price or parking tariff of that day, to make a trade and/or make a parking choice. An additional login into the web application is estimated to, all else being equal, result in an additional 2.44 cents on average. The activity level variable and age variable are demeaned. This means that the constant of model II can be interpreted as the deviation of the final budget from $€ 10$ for a participant that is of average age and displayed an average level of activity. When interpreting the estimate for the variable of activity level, one might wonder what this implies in terms of value of time. Let us say participants check the web application every now and then to obtain information about the current permit price and the trend. If it takes 15 seconds to open and check the current price ${ }^{2}$, the implied value of time is approximately $€ 6$. Participants are however also sampling for information which may make the payoff of checking the web application opaque to them. Furthermore, highly educated participants earned on average between $€ 0.40$ and $€ 0.45$ more than those who are not highly educated.

Regression model III is an extended and slightly adjusted version of model II, and overall results in similar estimates for most variables. Age is in this model included as two dummy variables, one for

\footnotetext{
${ }^{2}$ When having your smartphone already unlocked in your hand for any other purpose, checking the current price takes probably closer to 5 - 10 seconds. When having to pick your phone out of your pocket and login into the web application (because you have not done so before or logged out after your previous visit), checking the price is more likely to take 30 - 60 seconds.
} 
Table 2: Final budget OLS regressions

\begin{tabular}{|c|c|c|c|}
\hline & I & II & III \\
\hline constant & $\begin{array}{c}0.3172^{* *} \\
(0.1286)\end{array}$ & $\begin{array}{c}-0.2059 \\
(0.2711)\end{array}$ & $\begin{array}{c}-0.1815 \\
(0.3017)\end{array}$ \\
\hline \# of choices: 4 & $\begin{array}{c}-3.2986^{* * *} \\
(0.2499)\end{array}$ & $\begin{array}{c}-3.0026^{* * *} \\
(0.2495)\end{array}$ & $\begin{array}{c}-3.0069^{* * * *} \\
(0.3928)\end{array}$ \\
\hline \# of choices: 3 & $\begin{array}{c}-5.9844^{* * *} \\
(0.2977)\end{array}$ & $\begin{array}{c}-5.6807^{* * *} \\
(0.3133)\end{array}$ & $\begin{array}{c}-9.4681^{* * *} \\
(1.2615)\end{array}$ \\
\hline activity level & & $\begin{array}{c}0.0244^{* * *} \\
(0.0059)\end{array}$ & $\begin{array}{c}0.0242^{* * *} \\
(0.0059)\end{array}$ \\
\hline activity lvl $\cdot$ active_4 & & & $\begin{array}{c}0.0013 \\
(0.0299)\end{array}$ \\
\hline activity lvl · active_3 & & & $\begin{array}{c}0.7476^{* * *} \\
(0.2440)\end{array}$ \\
\hline age & & $\begin{array}{c}0.0010 \\
(0.0130)\end{array}$ & \\
\hline D $($ age $<38)$ & & & $\begin{array}{c}-0.0765 \\
(0.2395)\end{array}$ \\
\hline $\mathrm{D}($ age $>46)$ & & & $\begin{array}{l}-0.0253 \\
(0.2410)\end{array}$ \\
\hline university & & $\begin{array}{l}0.4099^{*} \\
(0.2242)\end{array}$ & $\begin{array}{c}0.4479^{* *} \\
(0.2163)\end{array}$ \\
\hline week 2 & & $\begin{array}{c}0.0580 \\
(0.2041)\end{array}$ & $\begin{array}{c}0.0744 \\
(0.1974)\end{array}$ \\
\hline high budget & & $\begin{array}{c}0.1722 \\
(0.2063)\end{array}$ & $\begin{array}{c}0.1031 \\
(0.2030)\end{array}$ \\
\hline woman & & $\begin{array}{c}-0.0711 \\
(0.2373)\end{array}$ & $\begin{array}{l}-0.0356 \\
(0.2325)\end{array}$ \\
\hline Obs. & 97 & 97 & 97 \\
\hline df & 94 & 88 & 85 \\
\hline$R^{2}:$ & 0.837 & 0.868 & 0.882 \\
\hline
\end{tabular}

being younger than 38 years old and one for being older than 46, which makes participants aged 38 to 46 fall in the reference category. These categories were chosen to divide participants into similar size groups based on age. Just as in regression model II, in which age was included as a demeaned level variable, results suggest that age has no effect on the final budget. One could hypothesize that older people are more likely to struggle with such an online experiment, but this hypothesis is not supported by the data.

The estimates for activity level, and whether or not participants have obtained a university degree, are very similar to those of model II. Two interaction terms were included to test if checking the web application has a different effect on final budgets for participants who make fewer parking choices than for those who make a choice on each day of the week. One included interaction is between a dummy variable for making choices on only 4 out of 5 days and the activity level. The other included interaction is between a dummy variable for making choices only 3 out of 5 days and activity level. The results in Table 2 show that the estimate for activity level itself is not really affected by including these interactions. For the interaction with the dummy for making 3 out of 5 parking choices, the estimate is highly significant and suddenly much larger. We also see that, for this group, the estimate for \# of choices: 3 has dropped considerably. The reason behind this is most likely the little variation in the number of logins within this group of participants, which means that there is a high level of 
collinearity between the interaction term and the dummy for this category, resulting in estimation difficulties for the interaction and dummy variable.

\subsection{Participant feedback}

A total of 79 participants filled out the survey, 4 of whom were non-active participants (participants who did not make a choice nor traded permits during the experiment). Approximately $26 \%$ of respondents is female and the average age was 44 (varying from 25 to 65). Almost all participants (95\%) indicated that they had read the instructions or watched the instruction video. $72 \%$ of participants is highly educated, having obtained at least a university bachelor degree. Graphs (a) and (b) of Figure 6 show that the tradability and purpose of the parking permits were clear to the large majority of participants. Determining the best parking choice was not difficult for most participants, as can be seen from graph (c). This is consistent with the high level of instantaneous rationality displayed in Figure 4. Most participants indicated that it was not difficult to determine the best trading strategy, although the answers to this question suggest that overall this took slightly more effort than determining the best parking choice. This is plausible, as the latter involves only the use of instantaneous information, while the former also requires the formation of expectations. Overall, most participants agreed with the statement that participating in the experiment took little time and effort (e). Finally, only few participants disagreed with the idea that tradable parking rights could sometimes be a good alternative for paid parking (f).

These responses to the survey questions paint a promising picture with respect to overall understanding and acceptability of a tradable permit scheme among the likely participants in such a scheme. Tradable permits for driving during the peak would, in its most simple set-up even be more simple to understand than our lab-in-the-field experimental set up, since our experiment also involves the making of a daily virtual mobility choice, which is not needed in a real life application. One might hypothesize that the acceptability of tradable parking rights as an alternative for paid parking is likely to be higher than the acceptability of tradable peak permits. The reason would be that Dutch participants are used to non-tradable parking permits and paid parking, but less used to paying (additionally) for travelling during the peak. This is a hypothesis that still has to be tested in the field.

\section{Conclusion and discussion}

We introduced a complete design for an efficient market for tradable mobility permits meant to ensure that transaction costs are very small. It does so by having a price setting bank, with which participants can freely and easily trade. The price against which permits can be bought from or sold to the bank is determined by a simple algorithm that has been selected to ensure that the market moves towards the mobility goal, while keeping price volatility low. The design has been tested with a lab-in-thefield experiment among experienced road users, which would be the target population in future field experiments. The choices participants faced were formulated as parking choices, and the experiment was designed to provide sufficient control over their preferences, so that we could circumvent the difficulty of jointly identifying true preferences and rationality of behaviour given these preferences. During the experimental implementation and the test of the designed market, the price stayed mostly within the equilibrium range, while the sum of used and currently owned permits stayed close to the defined policy goal. Investigation of participant behaviour shows that over $93 \%$ of parking choices were instantaneously rational, while most of the irrational choices where made when it mattered the least for their personal budgets. Both the responses from the conducted survey, and the actual behaviour during the experiment, support the notion that participants understood how to use and trade the permits. Participants indicated that making the choice was easy in their responses to survey questions. Analysis of the final budgets shows that participants did on average earn some additional money as a result of their trading behaviour, suggesting that at least some of them were able to take advantage of the changing price by trading smartly.

The analysis of the final budgets further showed that highly educated participants did on average earn approximately $€ 0.4$ more than the other participants. If future research shows that this is the case 
(a)

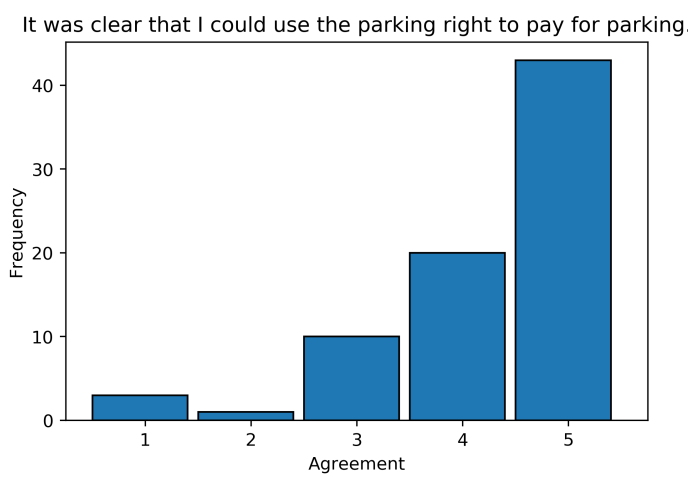

(c)

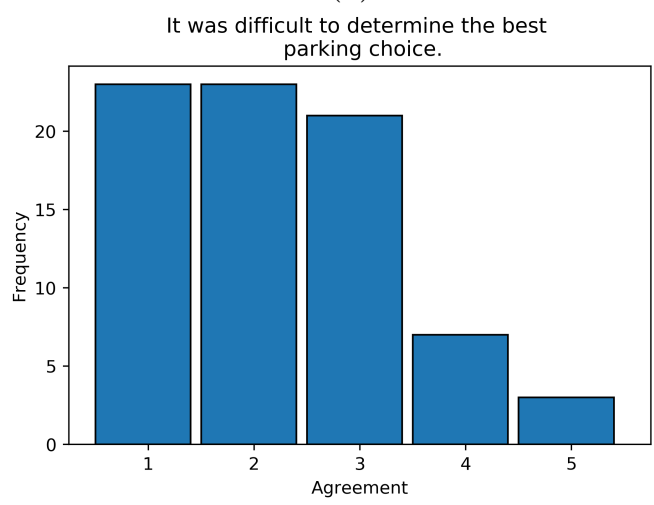

(e)

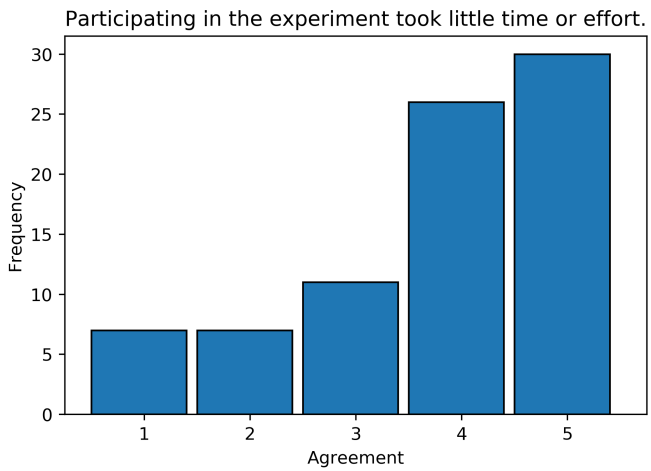

(b)

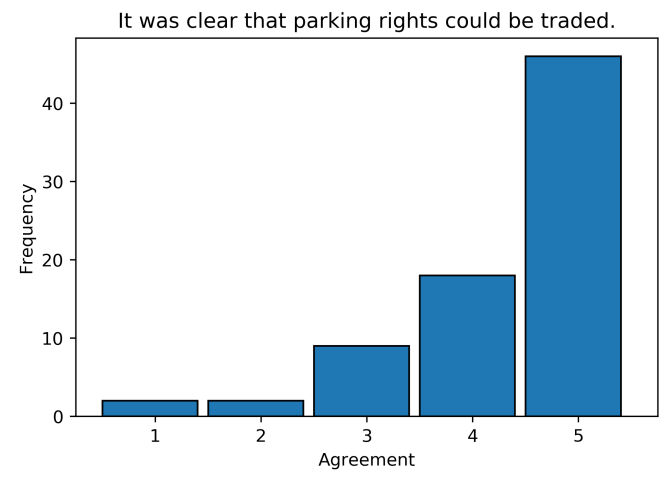

(d)

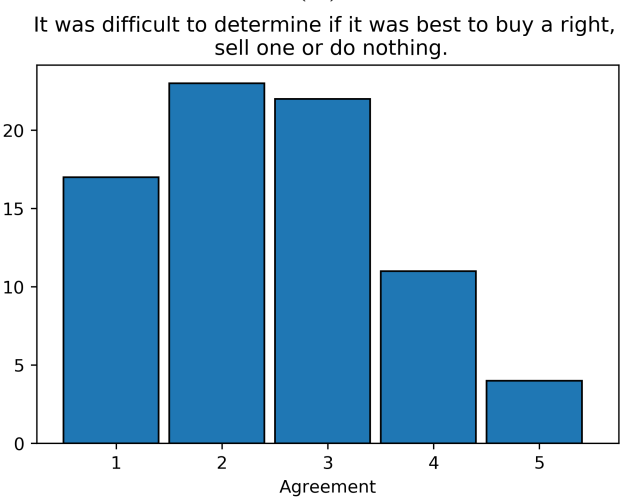

(f)

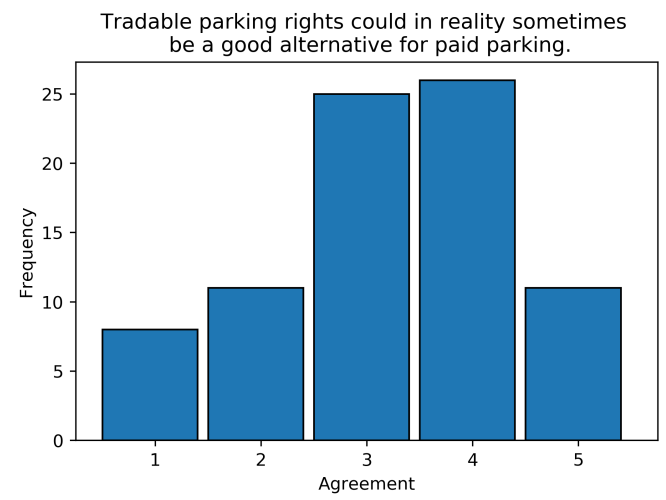

more generally when using tradable permit schemes, possible equity concerns could easily be addressed by adjusting the number of initially allocated permits accordingly.

One of the caveats of our lab-in-the-field experiment is that the response rate to the initial email invitation to participate in the experiment was 2-3\%. Possible explanations for this relatively low response rate cannot be deduced from our data. However, as the email invitation did not include specific instructions on what the experiment would comprise, the low response rate cannot be caused by a lack of understanding of the concept of tradable mobility permits. A second caveat is that a substantial number of participants did register for the experiment but did in the end not take any action in the web application (97 out of 180 registered participants). One possible explanation for this is that the experiment was conducted in December, which is a busy month for most people and includes the Dutch festivities of Sinterklaas. Another possible explanation is that these participants did not (fully) understand the organizational set-up of the experiment. A real field experiment would however be more simple in its set-up than the lab-in-the-field experiment, as participants would use 
permits by revealing actual peak behaviour, and make the trade-off between doing so or avoiding the peak and saving a permit. There is no complicated virtual choice in such as situation. Participants that do not understand the organizational set-up of the experiment would therefore be less of a concern in that case.

Overall, the results of the lab-in-the-field experiment are promising and support the notion that tradable permits can be a viable alternative to pricing in a transportation setting. Previous work has suggested this on the basis of modelling work in which efficient trading and efficient working of the market for tradable permits was pre-supposed. Our study confirms that individuals indeed do understand and use a system of tradable mobility permits in the way this is intended from underlying theory. The presented and tested market design will be used in future research as part of a first field experiment with tradable mobility permits.

\section{References}

Akamatsu, T. and K. Wada (2017). Tradable network permits: A new scheme for the most efficient use of network capacity. Transportation Research Part C: Emerging Technologies 79, 178-195.

Baldursson, F. M. and J. T. Sturluson (2011). Fees and the efficiency of tradable permit systems: an experimental approach. Environmental and resource economics 48(1), 25-41.

Christiansen, A. C., A. Arvanitakis, K. Tangen, and H. Hasselknippe (2005). Price determinants in the eu emissions trading scheme. Climate Policy 5(1), 15-30.

Crocker, T. D. (1966). The structuring of atmospheric pollution control systems. The economics of air pollution $61,81-84$.

Dales, J. H. (1968). Pollution, Property, and Prices: An Essay in Policy-Making. Toronto: University of Toronto Press.

de Palma, A., S. Proost, R. Seshadri, and M. Ben-Akiva (2018). Congestion tolling-dollars versus tokens: A comparative analysis. Transportation Research Part B: Methodological 108, 261-280.

Hommes, C., J. Sonnemans, J. Tuinstra, and H. Van De Velden (2007). Learning in cobweb experiments. Macroeconomic Dynamics 11(S1), 8-33.

Joskow, P. L., R. Schmalensee, and E. M. Bailey (1998). The market for sulfur dioxide emissions. American Economic Review, 669-685.

Kahneman, D., J. L. Knetsch, and R. H. Thaler (1990). Experimental tests of the endowment effect and the coase theorem. Journal of political Economy 98(6), 1325-1348.

Knockaert, J., Y.-Y. Tseng, E. T. Verhoef, and J. Rouwendal (2012). The spitsmijden experiment: A reward to battle congestion. Transport Policy 24, 260-272.

Martin, R., M. Muûls, and U. J. Wagner (2015). The impact of the european union emissions trading scheme on regulated firms: What is the evidence after ten years? Review of environmental economics and policy 10(1), 129-148.

Nie, Y. M. (2012). Transaction costs and tradable mobility credits. Transportation Research Part B: Methodological 46(1), 189-203.

Nie, Y. M. and Y. Yin (2013). Managing rush hour travel choices with tradable credit scheme. Transportation Research Part B: Methodological 50,1-19.

Schmalensee, R., P. L. Joskow, A. D. Ellerman, J. P. Montero, and E. M. Bailey (1998). An interim evaluation of sulfur dioxide emissions trading. Journal of Economic Perspectives 12(3), 53-68.

Stavins, R. N. (1995). Transaction costs and tradeable permits. Journal of Environmental Economics and Management 29(2), 133-148. 
Tietenberg, T. H. (1985). Emissions trading, an exercise in reforming pollution policy. Resources for the Future.

Verhoef, E., P. Nijkamp, and P. Rietveld (1997). Tradeable permits: their potential in the regulation of road transport externalities. Environment and Planning B: Planning and Design 24(4), 527-548.

Xiao, F., Z. S. Qian, and H. M. Zhang (2013). Managing bottleneck congestion with tradable credits. Transportation Research Part B: Methodological 56, 1-14.

Yang, H. and X. Wang (2011). Managing network mobility with tradable credits. Transportation Research Part B: Methodological 45(3), 580-594. 